EPJ Web of Conferences 52, 04002 (2013)

DOI: $10.1051 /$ epjconf/20135204002

(c) Owned by the authors, published by EDP Sciences, 2013

\title{
Results on the spectrum and composition of cosmic rays from the IceTop air shower array of the IceCube Observatory
}

\author{
Serap Tilav ${ }^{1, a}$ \\ ${ }^{1}$ Univ. of Delaware, USA
}

\begin{abstract}
We report on measurements of the energy spectrum and mass composition of cosmic rays above $1 \mathrm{PeV}$ with the data taken during the construction phase of the IceTop and IceCube detectors. We discuss our current systematics and observation of a structure in the energy spectrum above $20 \mathrm{PeV}$ where the mass composition gets heavier than iron nuclei.
\end{abstract}

\section{Slides}

The slides of the talk can be found on the website of the symposium ISVHECRI 2012: https://indico.desy.de/conferenceOtherViews.py?view=standard\&confId=4594

\footnotetext{
atilav@udel.edu
} 